\title{
An Inter-Generational Effect of Socio-Economic Status on Education Attainment in South Africa
}

\author{
Thendo M. Ratshivhanda, Sevias Guvuriro \\ Department of Economics, University of the Free State (UFS), Bloemfontein, South Africa \\ Thendo.Ratshivhanda@absa.co.za, guvuriros@ufs.ac.za
}

\begin{abstract}
Higher socio-economic status (SES) empowers an individual to have more access to a variety of materials relevant to achievements in life than would otherwise be possible. In theory, a child's educational attainment can be influenced by hereditary and ecological variables; parents' achievements are prompting children to achieve, or a deliberate investment that parents undertake in their children's welfare, all suggestive of inter-generational effect in the process. A parent's SES may therefore play a significant role in the child's achievements. This paper attempts to determine the relationship between a parent's SES and a child's educational attainment and uses South African data collected at the national level. Employing descriptive statistics and OLS regressions, an inter-generational effect of parental SES positively influencing a child's educational attainment is established. The finding supports policies promoting education as a fundamental poverty and inequality fighting mechanism in South Africa.
\end{abstract}

Keywords: Academic attainment; inter-generational effect; socio-economic status; South Africa; well-being

\section{Introduction}

There is increasing interest in understanding the relationship between a parent's socio-economic status (SES) and a child's education attainment (Alhaidari et al., 2016; Stahl, Schober \& Spiess, 2018). A parent's SES affects the parent's education involvement in a child's life. The parent's education involvement is a multifaceted construct encompassing a parent's education involvement at home and at school, as well as a parent's academic socialisation (Benner, Boyle, \& Sadler, 2016; Hill et al., 2004; Hill \& Tyson, 2009). A parent's education involvement represents the required 'concerted cultivation' i.e. "deliberate and sustained effort to stimulate children's development and to cultivate their cognitive and social skills" (Cheadle \& Amato, 2011:681). A child's educational attainment directly affects his/her future economic participation and wellbeing. It is in this view that promoting education attainment is one priority when targeting the socioeconomic ills in developing countries. In South Africa, promoting education attainment is one avenue to address the historical and perpetual economic imbalances. Socio-economic status (SES) includes a person's positioning in the hierarchy of needs indicated by access to or control over some blend of esteemed wares; for example, riches, influence, and economic well-being (Caro, 2009; Considine \& Zappalà, 2002; Sirin, 2005). A comprehensive measure of family SES accounts for a parent's education, occupation prestige, family income and multi-dimensional operationalisation of a parent's education involvement (Benner et al., 2016; Eilertsen et al., 2016; Long \& Pang, 2016). The current study focuses specifically on a parent's education and employment status as constituent components of SES in assessing the child's educational attainment.

These SES indicators shape the home environment that is helpful for a child's learning. Benner et al. (2016) refer to the parent's education as a socio-demographic marker that may constrain the levels or amounts of educational involvement that the parents are able to provide and the effects of such involvement. For instance, less educated parents are more likely to express lower educational expectations for their children compared to educated parents (Carolan \& Wasserman, 2015), and hence limited academic socialization in the form of less (in) direct messages to children about school that communicate expectations of parents on their children's schooling and views around the importance of education (Cheadle \& Amato, 2011; Roksa \& Potter, 2011). Limited academic socialization also manifests in the form of lack of concrete discussions between parents and children in which parents promote and influence the development of their children's future educational and occupational plans. Hill and Tyson (2009) applauded academic socialization as a process that allows parents to provide their children with the tools necessary for independence and educational success. A parent's education is therefore one essential family context that influences children's consequent accomplishments as grown-ups (Ermisch \& Pronzato, 2010). In the South African context and as of 2017, only $4.5 \%$ of South Africans between the ages of 18 and 29 years were enrolled in a university institution - up from $4 \%$ in 2002 (Statistics South Africa, 2017). 
This is a mere increase of $0.5 \%$ over a period of fifteen years. Of the 766812 pupils who were enrolled at tertiary institutions in 2016 , approximately $66.4 \%$ were African; $18.7 \%$ were White; $7.8 \%$ were Indian/Asian, and 7.1\% were Coloured (Statistics South Africa, 2017); a distribution in line with South African demographics. Although this distribution shows that most of the students in the South African universities were of African descent, within the African youth group of ages 18 to 29 years, merely $3.3 \%$ were in school during the year 2016. This within-race percentage is the lowest compared to other races, which have $3.5 \%$ for Coloureds, $18.8 \%$ for Indians/Asians and $\mathbf{1 7 . 5 \%}$ for White South Africans (Statistics South Africa, 2017). Against this background, an important issue to consider - and hence the main focus of the current paper - is to seek to establish whether there is any discernible relationship between a parent's SES and the academic achievement of a child. Specifically, the paper attempts to establish if the parent's education and employment status explain the child's educational attainment within the South African context. The remainder of the paper is structured as follows. Section 2 provides a literature review. Data and methods are presented in section 3. Section 4 presents the results. Section 5 gives a discussion and, finally, section 6 concludes the exposition.

\section{Literature Review}

Theory: The positive relationship between a parent's SES and a child's educational attainment has various conceivable explanations. The pure selection theory holds that a parent with more education has a child who will do as such (Black, Devereux, \& Salvanes, 2005). In terms of this theory, qualities that lead parents to choose elevated levels of education may be identified with other hereditary and ecological variables imparted to their children that will lead the children, likewise, to accomplish elevated levels of education (Dickson, Gregg, \& Robinson, 2016). In addition, children of educated parents may also aim to emulate their parents. In this manner, a positive correlation between the parent's SES and the child's educational attainment is a norm rather than a chance event. The causal theory, another plausible explanation, suggests that acquiring more education makes one a different kind of a parent that may also prompt their children to attain higher educational outcomes (Black et al., 2005). Large amounts of schooling enable parents to give superior experience and home conditions to their children - such that the children improve on their schooling (Black et al., 2005; Chevalier, 2004; Dickson et al., 2016). Chevalier (2004) further states that highly educated parents provide an environment that enhances their children's opportunities and choice procedures. This parent SES measure is stable, established at an early age by the parents and has a tendency to remain the same (Sirin, 2005). Family environment may advance procurement of numeric skills that relate to parents' educational achievements and their abilities (Ermisch \& Pronzato, 2010). These intellectual incitements relate to better academic achievements by children.

Investment theory, however, posits that children's success in school depends on the investments that parents, among other stakeholders, make in the child's education (Stevens \& Schaller, 2011). In terms of this theory a child's education enters into the parent's spending function, both in terms of time and monetary values. This means that the availability of resources as influenced by the parent's SES plays a crucial role in the child's educational attainment. Willingham (2012), for instance, argues that low-salary families cannot as promptly manage the costs of books, computers, access to tutors and different sources of academic support. Advanced education expands the ability to earn income in the market and, in turn, entails spending more income on everything that parents esteem - including their children's education (Black et al., 2005; Ermisch \& Pronzato, 2010; Sirin, 2005). Parents' education accomplishments may also change their attitude towards investment in their children, for example, by reading to the child, an engagement that may influence children's goals (Ermisch \& Pronzato, 2010). Investment theory, likewise, suggests that a parent's SES assumes a noteworthy role in providing educational resources and imposes a stronger influence on the child's educational success.

Empirical literature: A probit model to explain the effects of the number of years of a parent's education and income on their children's education level by (Chevalier, 2004) and using UK data, establishes that increasing a parent's education by one year builds the likelihood of a child remaining at school by 4 percentage points. The model results also show that the combined effects of the mother and father's education on child's education are similar in magnitudes and that children living in higher income homes are more likely to obtain a higher level of education. Chesters (2010) estimates a logistic model to test the effects of a parent's education on child education, using three different eras to compare the outcomes between 1987 
and 2005 in Australia and finds that both the father and the mother's education have a positive influence on the child's education, with the mother's carrying more weight.

Black et al. (2005) find a minimal causal relationship between a parent's education and a child's education in spite of strong ordinary least squares relationships, using Norwegian data. A Norwegian data based twinanalysis testing whether child's education is dependent entirely on either genes or their common childhood environment (by gathering the impact of the parent's education on the child's education net of any hereditary impacts) suggests other aspects than just growing up in a similar environment with the same parents (Ermisch \& Pronzato, 2010). In terms of a parent's employment status, Usaini and Abubakar (2015) use an OLS regression model on Malaysian data to investigate the effect of a parent's employment status on a child's academic performance. Usaini and Abubakar (2015) find that parents' employment status influences academic performance in secondary school, such that students whose parents had better jobs in the formal sector had better marks and performed better in school than the students whose parents worked in the informal sector or were unemployed. "When parents have a better occupation, they provide economic, social, psychological and emotional support to their children, and this would make it possible for the children to perform well in their educational attainment" (Usaini \& Abubakar, 2015:114).

In a study by Ngare et al. (2017), it is reported that parents with less-esteemed occupations or who were unemployed neglected to make these sufficient arrangements to support their children in their educational accomplishment, which could result in poor academic performance or even dropouts. Employing ANOVA in determining the significance of parents' employment status and family income on a child's education attainment and using Pakistan data, Shah and Anwar (2014) showed that both a mother and a father's employment status have a positive and significant effect on a child's education, with a father's being greater. While the positive impact of these parents' SES indicators is mostly reported, other studies report the possibility of parents who are not employed being advocates of education and therefore inspiring their children to do better at school. Considine \& Zappalà (2002) argue that parents may have a low salary and a low-status occupation but transmitting high education desires to their kids. Schildberg-Hörisch (2016) suggests a negative relationship between parents with high-status occupation and child education attainment, as high-status employment diminishes time spent at home with the children. Parents in such circumstances were detached from their children's schoolwork. The current paper employs South African data, collected at the national level, to assess the impact of a parent's education and employment status on a child's educational attainment.

\section{Data and Methods}

In this paper, we make use of National Income Dynamics Study (NIDS) data, a national survey carried out in South Africa. The paper initially assesses the relationship between a parent's education and employment status and a child's educational attainment descriptively, and then precedes to using regression models in determining the extent to which a child's educational attainment is explained by the parent's education and employment status. Sub-group analyses that take cognisance of race and gender factors are carried out to get more nuanced results. Specifically, wave 4 data (collected in 2014) of the NIDS project are used. The adult questionnaire of the survey collects information from respondents about their families, education and employment status, among other things. Extensive information on the respondent's education history and the education and occupation history of the parents of the respondents are available. A sample of 26534 adults was successfully interviewed for this wave and this paper restricts the sample to adults of age range 15 to 64 years, remaining with a sample of 24427 adults. The dependent variable in the analysis is the child's education with values ranging from 0 (when a respondent has no formal education at all or 0 years of education) to 18 years (highest possible academic qualification - which is a Master's or Doctoral degree).

The main covariate is the parent's SES represented by its indicators; that is the parent's education and the parent's employment status. A parent's education similarly ranges from 0 to 18 years, whereas unemployment status is a binary variable assuming the value 0 (=unemployed) or 1 (= employed). Based on the available literature, we expected both parents' education and employment status to influence the child's educational attainment positively. In addition, and as controls, age, race and gender of the child are included in the analysis. The gender variable is a binary variable taking the value 1 if female and 0 if male. The race 
variable has four categories: 0 (= African), 1 (= Coloured), 2 (= Indian/Asian), and 3 (= white). Given the South African historical background, previously disadvantaged groups in South Africa are less likely to obtain a formal education because of the lack of opportunities and/or money. A priori, female individuals are less likely to attain higher levels of formal education than their male counterparts are.

The paper also makes use of sub-group analysis to report the effects of a parent's SES on a child's educational attainment, based on race and gender. The variables in the analyses, therefore, are the child's education attainment (childeduc), the mother's highest education level $\left(H E_{M}\right)$, the father's highest education level $\left(H E_{F}\right)$, the mother's employment status $(O c c M)$, the father's employment status $(O c c F)$, and age, race and gender of the respondent/child. Turning to the econometric models, Ordinary Least Squares (OLS) regression models are used. Model 1 and Model 2 assess the influence of a parent's education and a parent's employment status respectively and are expressed as follows:

childeduc $=\beta_{0}+\beta_{1} H E_{M}+\beta_{2} H E_{F}+\beta_{3}$ Age $+\beta_{4}$ Race $+\beta_{5}$ Gender $+\varepsilon_{i}$

childeduc $=\beta_{0}+\beta_{1}$ Occ $M+\beta_{2}$ OccF $+\beta_{3}$ Age $+\beta_{4}$ Race $+\beta_{5}$ Gender $+\varepsilon_{i}$

In addition, goodness of fit tests are conducted comparing the variance explained statistics of Model 1 and Model 2, and also conducting the F-tests for the two models. Further, a complete model (Model 3) with two SES indicators is given as:

childeduc $=\beta_{0}+\beta_{1} H E_{M}+\beta_{2} H E_{F}+\beta_{3} O c c M+\beta_{4} O c c F+\beta_{5}$ Age $+\beta_{6}$ Race $+\beta_{7}$ Gender $+\varepsilon_{i}$

Sub-group regression models are represented by Model 4 and Model 5 as:

childeduc $=\beta_{0}+\beta_{1} H E_{M}+\beta_{2} H E_{F}+\beta_{3} O c c M+\beta_{4} O c c F+\beta_{5}$ Age $+\beta_{7}$ Gender $+\varepsilon_{i}$

childeduc $=\beta_{0}+\beta_{1} H E_{M}+\beta_{2} H E_{F}+\beta_{3} O c c M+\beta_{4} O c c F+\beta_{5}$ Age $+\beta_{6}$ Race $+\varepsilon_{i}$

So, Model 4separates the respondents by race while Model 5 separates the respondents by gender.

\section{Results}

Descriptive statistical results are presented in Tables 1 and 2, followed by regression results in Tables 3 to 5 . The respondent's education is about 9 years on average, with a median value of around 10 years. However, mean education level is higher for male respondents compared to female respondents, though with no statistical significance on this difference. The mother's highest education has mean and median values of approximately 4 years, while the father's highest education level is approximately 4 years on average and the median value 0 years. It is interesting to note that children/respondents, on average, have achieved more than double their father and mother's educational attainment. Most of the parents of the respondents in this study do not have a formal education - as percentages of reported zeros in terms of mother's and father's education are $54.91 \%$ and $55.33 \%$ respectively, while the percentage of zeros for formal education for respondents is a mere $9.4 \%$. Approximately $95 \%$ of the educational attainment for both respondents and parents fall within two standard deviations of the mean. In terms of the parent's employment status, about $46 \%$ of the mothers were employed whereas $69 \%$ of the fathers were employed, clearly showing that the respondents' mothers are more likely than the fathers to be unemployed. This sample is in line with the South African population demographics consisting mostly of Africans (83.4\%), followed by Coloureds (13.8\%), then Whites (1.8\%), and lastly Indians/Asians (0.9\%). The average age of the respondents was 34 years, of which the males' average age was 32 years and that of females 35 years. White respondents were on average more educated than their African, Coloured and Indian/Asian counterparts. The average years of education for Whites is 12 years while for the other races, the average values lie between 9 - 10 years. Similarly, White parents on average were more educated than the African, Coloured and Indian/Asian parents, having double the education of the Africans and Coloureds.

This trend is also evident concerning employment status. Evidence of the influence of SES in its different forms on the child's educational attainment is presented next. Table 3 shows, as expected, a positive relationship between the parent's education and the child's educational attainment. The estimates for model 1 suggests that increasing the mother's education and the father's education by a year respectively raises, and statistically significantly so, the child's education attainment by 0.17 years and 0.12 years. Black et al. (2005); Dickson et al. (2016) and Ermisch and Pronzato, (2010) also reported statistically significant results in similar studies. Model 2 shows that employed parents are more likely to have children who attain higher 
levels of education, reporting statistically significant coefficients of 0.70 and 0.63 for mother and father respectively. When the two SES indicators are included in the same model (Model 3), positive results are consistent for both parent's education and parent's employment status. Model 3 also shows that coefficients for parent's education are closer to those of Model 1 but the coefficients for parent's employment status drop in magnitude, compared to those in Model 2. The consistency of results across the models is also reported for the control variables - which are age, race and gender of the child/respondent. While the age of the respondent has a negative relationship with his/her education attainment, possibly because the dawn of democracy in South Africa opened doors for the young generation to attain higher levels of education, the race factor shows that Whites and Indians fare.

Table 1: Descriptive Statistics

\begin{tabular}{|c|c|c|c|c|c|c|c|c|c|c|c|c|c|}
\hline & \multicolumn{5}{|c|}{ Total sample } & \multicolumn{4}{|c|}{ Male child } & \multicolumn{4}{|c|}{ Female child } \\
\hline & Mean & Median & $\begin{array}{l}\text { Std. } \\
\text { Dev }\end{array}$ & $\begin{array}{l}\text { \% of } \\
\text { zeros }\end{array}$ & $\begin{array}{l}\text { Sample } \\
\text { (n) }\end{array}$ & Mean & Median & $\begin{array}{l}\text { Std. } \\
\text { Dev }\end{array}$ & $\begin{array}{l}\text { Sample } \\
\text { (n) }\end{array}$ & Mean & Median & $\begin{array}{l}\text { Std. } \\
\text { Dev }\end{array}$ & $\begin{array}{l}\text { Sample } \\
\text { (n) }\end{array}$ \\
\hline childeduc & 9.34 & 10 & 3.48 & $9.4 \%$ & 22,133 & 9.36 & 10 & 3.23 & 8,832 & 9.21 & 10 & 3.6 & 11,917 \\
\hline $\mathrm{HE}_{\mathrm{M}}$ & 4.46 & 4 & 4.54 & $54.91 \%$ & 11,014 & 4.91 & 5 & 4.65 & 4,372 & 4.16 & 3 & 4.45 & 6,642 \\
\hline $\mathrm{HE}_{\mathrm{F}}$ & 4.02 & 0 & 4.7 & $55.33 \%$ & 10,910 & 4.44 & 3 & 4.8 & 4,531 & 3.73 & 0 & 4.61 & 6,379 \\
\hline $\mathrm{OccF}$ & 0.69 & 1 & 0.46 & $67.48 \%$ & 10,944 & 0.71 & 1 & 0.46 & 4,759 & 0.67 & 1 & 0.47 & 6,185 \\
\hline Age & 34 & 31 & 13.78 & $0 \%$ & 24,427 & 32 & 28 & 13.52 & 8,850 & 35 & 32 & 14.09 & 11,931 \\
\hline Gender & 0.57 & 1 & 0.49 & $14.93 \%$ & 20.781 & - & - & - & - & - & - & - & - \\
\hline
\end{tabular}

Notes: Childeduc $=$ respondent's education; $\mathrm{HEM}_{\mathrm{M}}=$ Mother's highest education; $\mathrm{HE}_{\mathrm{F}}=$ Father's highest education; OCCM = Mother's employment status; OCCF = Father's employment status; Std. Dev = standard deviation.

Table 2: Descriptive Statistics, by Race

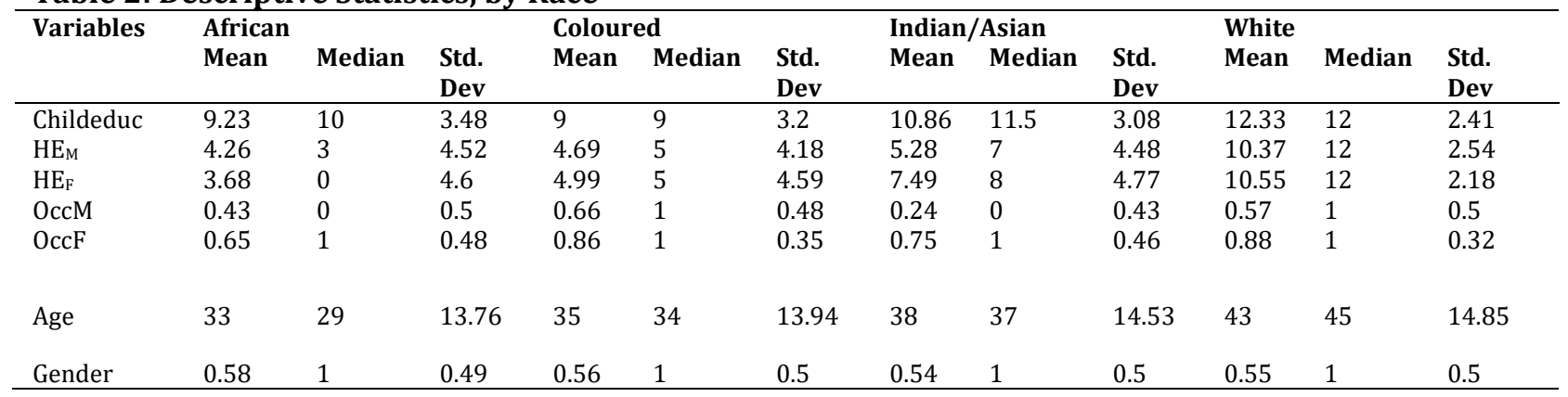

Notes: Childeduc $=$ respondent's education; $\mathrm{HE}_{\mathrm{M}}=$ Mother's highest education; $\mathrm{HE}_{\mathrm{F}}=$ Father's highest education; OCCM = Mother's employment status; OCCF = Father's employment status; Std. Dev = standard deviation.

Table 3: Determinants of a child's Education Attainment

\begin{tabular}{llll}
\hline Variables & Model 1 & Model 2 & Model 3 \\
\hline Mother's highest education & $0.175^{* * *}$ & - & $0.1659^{* * *}$ \\
Father's highest education & $(0.0116)$ & & $(0.0135)$ \\
& $0.1279^{* * *}$ & - & $0.1341^{* * *}$ \\
Mother's employment status & $(0.0111)$ & & $(0.0129)$ \\
& - & $0.7026^{* * *}$ & $0.3879^{* * *}$ \\
Father's employment status & - & $(0.0786)$ & $(0.0966)$ \\
Age & $-0.0802^{* * *}$ & $0.6357^{* * *}$ & $0.474^{* * *}$ \\
Base outcome: African $=0$ & $(0.0034)$ & $-0.0876)$ & $(0.1075)$ \\
& & $(0.003)$ & $-0.0783^{* * *}$ \\
\end{tabular}

Base outcome: African $=0$ 


\begin{tabular}{llll}
\multicolumn{4}{c}{$\begin{array}{l}\text { Journal of Economics and Behavioral Studies (ISSN: 2220-6140) } \\
\text { Vol. 10, No. 4, pp. 252-261, August 2018 }\end{array}$} \\
\hline \hline \multicolumn{4}{c}{} \\
\hline Coloured=1 & -0.1092 & $-0.2365^{* *}$ & $-0.4658^{* * *}$ \\
Indian/Asian= 2 & $(0.1132)$ & $(0.1089)$ & $(0.1289)$ \\
White= 3 & $2.688^{* * *}$ & $2.8079^{* * *}$ & $2.2714^{* * *}$ \\
Gender & $(0.3889)$ & $(0.3567)$ & $(0.3953)$ \\
Const. & $2.7233^{* * *}$ & $4.535^{* * *}$ & $2.3627^{* * *}$ \\
Obs. & $(0.2015)$ & $(0.1887)$ & $(0.218)$ \\
& -0.0484 & -0.079 & -0.0982 \\
& $(0.0798)$ & $(0.0754)$ & $(0.0908)$ \\
& $10.8709^{* * *}$ & $12.4397^{* * *}$ & $10.4887^{* * *}$ \\
& $(0.1569)$ & $(0.1235)$ & $(0.1905)$ \\
& 7341 & 7755 & 5429 \\
\hline
\end{tabular}

Notes: ${ }^{*}, * *, * *$ denote significance at $10 \%, 5 \%$ and $1 \%$ levels. Robust standard errors are in parentheses.

Sub-group analyses on race are reported in Table 4. The results show that, except for the Indian child, the mother's education boosts the child's education attainment for all races significantly. The highest coefficient for the mother's education is for Whites (0.3293), followed by that for Coloureds (0.2319) and lastly that of Africans (0.1489). In the case of father's education, the highest coefficient is reported for Indians (0.3209), followed by Whites (0.249), then Coloureds (0.2217), and lastly Africans (0.1145). This seems to suggest that giving an extra year of education to a White mother is more economically significant than giving a same year to an African mother, for instance. However, the trend of results may also not be surprising as culturally we expect African mothers to have a wide array of responsibilities within the household, other than assisting the children with schoolwork or education socialisation in general. The generally low level of education for African parents could also be playing a role in dampening the coefficients of parent's education as a covariate. With sub-group analyses, it is clear that the employment factor plays a statistically significant role only among Africans.

When the African mother or father is employed, the child's educational attainment is raised statistically significantly. This is crucial as employment is a source of income and generally helps to reduce poverty that is predominant among African families. Here, the age of the respondent/child for the African and Coloured continued to bear a negative sign, and significantly so. However, that of the White child is positive and significant. Such results are a clear indication of the advantages that a White child enjoyed even before the dawn of democracy, but also the advantages of the dawn of democracy in South Africa that opened doors for other races, and hence by age now shows negative correlations. The gender of the child/respondent does not influence educational attainment in this South African sample. This is possible because South Africa has embraced the Millennium Development Goals, and has reported success in educating a girl child in the same way as a boy child. The r-squared values for the three models are relatively high, indicating acceptable goodness of fit. The race results are a clear testimony of the perpetuating disparities in South Africa, the aftermath of the Apartheid era, with White parents showing positive and significant influence on children education attainment. Lastly, being African shows a better outcome on child's education than being Coloured while being Indian and White show a better outcome than being African, irrespective of child's gender. Largely, this confirms the success in giving equal education opportunities to both a girl and a boy child. 
Table 4: Determinants of a Child's Education Attainment, By Race

\begin{tabular}{lllll}
\hline Variables & \multicolumn{4}{l}{ Regression models for race clusters } \\
& Black & Coloured & Indian/Asian & White \\
\hline Mother's highest education & $0.1489^{* * *}$ & $0.2319^{* * *}$ & 0.0608 & $0.3293^{* * *}$ \\
& $(0.0148)$ & $(0.0378)$ & $(0.1063)$ & $(0.0792)$ \\
Father's highest education & $0.1145^{* * *}$ & $0.2217^{* * *}$ & $0.3209^{* * *}$ & $0.249^{* * *}$ \\
& $(0.0142)$ & $(0.0361)$ & $(0.1041)$ & $(0.0812)$ \\
Mother's employment status & $0.4768^{* * *}$ & -0.0009 & -0.8044 & 0.3855 \\
& $(0.107)$ & $(0.2688)$ & $(0.9617)$ & $(0.3828)$ \\
Father's employment status & $0.5513^{* * *}$ & -0.1359 & $-1.3773^{*}$ & -0.2058 \\
& $(0.1142)$ & $(0.3626)$ & $(0.0349)$ & $(0.4449)$ \\
Age & $-0.0878^{* * *}$ & $-0.0485^{* * *}$ & 0.01759 & $0.0341^{* *}$ \\
& $(0.0044)$ & $(0.01)$ & $(0.0349)$ & $(0.0159)$ \\
Gender & -0.0946 & -0.0947 & -0.8519 & 0.188 \\
& $(0.1017)$ & $(0.2319)$ & $(0.6504)$ & $(0.3312)$ \\
Const. & $10.8988^{* * *}$ & $8.9259^{* * *}$ & $10.3932^{* * *}$ & $5.0182^{* * *}$ \\
& $(0.2114)$ & $(0.5586)$ & $(1.4874)$ & $(1.4251)$ \\
Obs. & 4519 & 687 & 46 & 177 \\
& & & & \\
& 0.2827 & 0.3459 & 0.3395 & 0.1990
\end{tabular}

Notes: ${ }^{*}, * *, * *$ denote significance at $10 \%, 5 \%$ and $1 \%$ levels. Standard errors are in parentheses.

As a confirmation of no gender differences in terms of the effects of the SES indicators and other control variables, Table 5 shows exactly the same results with respect to statistical significance. A parent's education is highly significant irrespective of the gender of the child. A parent's employment status is a significant factor, and highly so for the girl child. The age of the child carries a negative sign and significantly so irrespective of the gender.

Table 5: Determinants of a Child's Education Attainment, by Gender Regression models for gender clusters

\begin{tabular}{lll} 
Variables & Male & Female \\
\hline Mother's highest education & $0.1138^{* * *}$ & $0.2124^{* * *}$ \\
& $(0.0198)$ & $(0.0183)$ \\
Father's highest education & $0.131^{* * *}$ & $0.1325^{* * *}$ \\
& $(0.0188)$ & $(0.0176)$ \\
Mother's employment status & $0.3824^{* *}$ & $0.3989^{* * *}$ \\
& $(0.1489)$ & $0.1261)$ \\
Father's employment status & $0.3174^{*}$ & $0.5321^{* * *}$ \\
Age & $(0.1656)$ & $(0.14)$ \\
Baseline outcome: African $=0$ & $-0.0622^{* * *}$ & $-0.0901^{* * *}$ \\
Coloured $=1$ & $(0.0061)$ & $(0.0051)$ \\
& & \\
\hline
\end{tabular}




\begin{tabular}{lll} 
& Journal of Economics and Behavioral Studies (ISSN: 2220-6140) \\
Vol. 10, No. 4, pp. 252-261, August 2018 \\
\hline \hline
\end{tabular}

Notes: ${ }^{*}, * *, * * *$ denote significance at $10 \%, 5 \%$ and $1 \%$ levels. Standard errors are in parentheses.

Discussion: Education attainment in its own right is an important opportunity, particularly for children from economically poor households as it helps them overcome the inconvenience of their frayed background. It sets the previously disadvantaged on an equivalent balance with the previously advantaged when entering the work environment and even at the workplace. The SES of the families where children come from is thus crucial as it affects their education accomplishment (Taylor \& Yu, 2009). The parent's SES can therefore block the child from catching up in terms of well-being, simply because they are inheriting poverty and its ugly dimensions. In this paper, the claim of parent's education positively influencing the child's educational attainment is confirmed, concurring with notions of educated parents having higher expectations for their children, but also the existence of academic socialisation in such families (Hill \& Tyson, 2009). A causal theory is playing out to some extent as high education for parents begets higher education for their children. The parent's employment status, a proxy for the provision of economic, social, psychological and emotional support, is also an important determinant of a child's educational attainment. Here, the investment theory is confirmed as employment status is a sign of (UN) availability of resources. Such resources enable parents to fulfil their esteemed goals, including their children's educational achievements. The extent of the analysis carried out in this paper cannot categorically support or refute the pure selection theory, calling for in-depth data collection that enables such rigorous analysis.

\section{Conclusion}

This study focused on the influence of a parent's education and employment status, described as SES components, on a child's educational attainment. These SES components directly inform a parent's education involvement that happens at home, at school, as academic socialisation and as concerted cultivation. An additional outcome of this paper focused on the impact of race, the impact of gender in the form of the influence of the mother's SES compared to the father's SES as well as the gender of a child. The positive and statistically significant effects of parents' SES components on children's education attainment augurs well with policies promoting education in South Africa as a fundamental inequality fighting mechanism. This result supports the efforts of the South African government to provide education to children and employment opportunities for parents. However, the result also calls for intervention measures - especially to children from households with parents who have no or little education.

Lack of proper academic socialisation at home may result in efforts of free education to children from previously disadvantaged families being in vain. The paper has shown that SES components inform parents and therefore families' capacities to confront the economic and social ills that characterise many South African households. An indication that follows from the analysis of this paper is that for households whose SES is low there is a need for appropriate and direct intervention to break the negative inter-generational effect that would imply poverty inheritance. The paper takes note of the limited number of measures of SES employed here, namely education and binary employment status. Further studies may benefit literature by adding more measures of SES such as income level, wealth level and interaction of both parents' SES measures. In addition, a specific look at the quality of education and not just the level of education as well as specific occupations of the parents as opposed to the status of being employed or not may add to this line of literature. 


\section{References}

Alhaidari, S. I., Al Houssien, A. O., Alteraiqi, M. A., Al Arafah, A. M., Al Houssien, R. O., Alhaidari, O. I. \& Omair, A. I. (2016). Children's growth pattern and mothers' education and socioeconomic status in Riyadh, Saudi Arabia. Journal of Health Specialties, 4(4), 276-281.

Benner, A. D., Boyle, A. E. \& Sadler, S. (2016). Parental involvement and adolescents' educational success: The roles of prior achievement and socioeconomic status. Journal of Youth and Adolescence, 45(6), 10531064.

Black, S. E., Devereux, P. J. \& Salvanes, K. G. (2005). Why the apple doesn't fall far: Understanding intergenerational transmission of human capital. American Economic Review, 95(1), 437-449.

Caro, D. H. (2009). Socio-Economic Status and Academic Achievement Trajectories from Childhood to Adolescence. Canadian Journal of Education, 32(3), 558-590.

Carolan, B. V. \& Wasserman, S. J. (2015). Does parenting style matter? Concerted cultivation, educational expectations, and the transmission of educational advantage. Sociological Perspectives, 58(2), 168186.

Cheadle, J. E. \& Amato, P. R. (2011). A quantitative assessment of Lareau's qualitative conclusions about class, race, and parenting. Journal of Family Issues, 32(5), 679-706.

Chesters, J. (2010). Has the effect of parents' education on child's education changed over time? Australian National University, Centre for Economic Policy Research.

Chevalier, A. (2004). Parental education and child's education: a natural experiment, 1153.

Considine, G. \& Zappalà, G. (2002). Factors influencing the educational performance of students from disadvantaged backgrounds. In Competing visions: Refereed proceedings of the national social policy conference, 91-107.

Dickson, M., Gregg, P. \& Robinson, H. (2016). Early, late or never? When does parental education impact child outcomes? The Economic Journal, 126(596), 184-231.

Eilertsen, T., Thorsen, A. L., Holm, S. E. H., Bøe, T., Sørensen, L. \& Lundervold, A. J. (2016). Parental socioeconomic status and child intellectual functioning in a Norwegian sample. Scandinavian Journal of Psychology, 57(5), 399-405.

Ermisch, J. \& Pronzato, C. (2010). Causal effects of parents' education on children's education. ISER Working Paper Series.

Hill, N. E., Castellino, D. R., Lansford, J. E., Nowlin, P., Dodge, K. A., Bates, J. E. \& Pettit, G. S. (2004). Parent academic involvement as related to school behavior, achievement, and aspirations: Demographic variations across adolescence. Child Development, 75(5), 1491-1509.

Hill, N. E. \& Tyson, D. F. (2009). Parental involvement in middle school: a meta-analytic assessment of the strategies that promote achievement. Developmental Psychology, 45(3), 740.

Long, H. \& Pang, W. (2016). Family socioeconomic status, parental expectations, and adolescents' academic achievements: a case of China. Educational Research and Evaluation, 22(5-6), 283-304.

Ngare, N. N., Maronga, E., Tikoko, B. \& Sigei, J. (2017). Parental occupation as a predictor of student's academic performance, in Kenya certificate of secondary education in public mixed day secondary schools in nyamira north sub-county, Kenya. Kabarak Journal of Research \& Innovation, 4(2), 70-83.

Roksa, J. \& Potter, D. (2011). Parenting and academic achievement: Intergenerational transmission of educational advantage. Sociology of Education, 84(4), 299-321.

Schildberg-Hörisch, H. (2016). Parental employment and children's academic achievement. IZA World of Labor.

Shah, M. A. A. \& Anwar, M. (2014). Impact of Parent's Occupation and Family Income on Children's Performance. International Journal of Research, 1(9), 606-612.

Sirin, S. R. (2005). Socioeconomic status and academic achievement: A meta-analytic review of research. Review of Educational Research, 75(3), 417-453.

Stahl, J. F., Schober, P. S. \& Spiess, C. K. (2018). Parental socio-economic status and childcare quality: Early inequalities in educational opportunity? Early Childhood Research Quarterly, 44 (3 ${ }^{\text {rd }}$ Quarter), 304317.

Statistics South Africa. (2017). General Household Survey 2016. Statistical Release P0318.

Stevens, A. H. \& Schaller, J. (2011). Short-run effects of parental job loss on children's academic achievement. Economics of Education Review, 30(2), 289-299. 
Taylor, S. \& Yu, D. (2009). The importance of socio-economic status in determining educational achievement in South Africa. Unpublished Working Paper (Economics). Stellenbosch: Stellenbosch University.

Usaini, M. I. \& Abubakar, N. B. (2015). The impact of parents' occupation on academic performance of secondary school students in Kuala Terengganu. Multilingual Academic Journal of Education and Social Sciences, 3(1), 115.

Willingham, D. T. (2012). Ask the Cognitive Scientist: Why Does Family Wealth Affect Learning. American Educator, 36(1), 33-39. 